\title{
PEMERATAAN BEBAN PADA GARDU KD 056 PENYULANG TABANAN PT PLN (PERSERO) DISTRIBUSI BALI AREA BALI SELATAN
}

\author{
I Putu Agus Semara Putra, ${ }^{1}$ I Ketut Wijaya, ${ }^{2}$ I Made Mataram. ${ }^{3}$ \\ ${ }^{123}$ Program Studi Teknik Elektro Fakultas Teknik Universitas Udayana \\ Email: semaraputra94@yahoo.co.id ${ }^{1}$ wijaya@ee.unud.ac.id ${ }^{2}$ \\ mataram@unud.ac.id $^{3}$
}

\begin{abstract}
Abstrak
Penyeimbangan beban gardu distribusi merupakan suatu rutinitas yang dilakukan oleh PLN dalam rangka manajemen sebuah gardu distribusi. Penyeimbangan beban dilakukan pada Waktu Beban Puncak (WBP) saja. Pengukuran awal beban dan data beban pada sebuah trafo distribusi perlu dilakukan untuk penyeimbangan sebagai input software simulasi. Ketidakseimbangan beban pada suatu sistem distribusi tenaga listrik disebabkan karena ketidakseimbangan pada beban-beban satu fasa pada phasa $R, S$ dan $T$ di dalam jaringan tegangan rendah. Akibat ketidakseimbangan beban tersebut timbullah arus di netral trafo. Arus yang mengalir di netral trafo ini menyebabkan terjadinya losses (rugi-rugi), yaitu losses akibat adanya arus netral pada penghantar netral trafo dan losses akibat arus netral yang mengalir ke tanah. Pada penelitian ini pemerataan beban gardu KD 056 dilakukan dengan membuat simulasi pada program ETAP dengan melakukan pengukuran nilai tegangan pada gardu KD 056. Hasil penyeimbangan beban gardu KD 056 dengan simulasi program ETAP yaitu drop tegangan yang didapat hasil persentase gardu KD 056 setelah diseimbangkan drop tegangan pada phasa $R$ berkurang dari $7,30 \%$ menjadi $1,36 \%$ dari tegangan sumber $219 \mathrm{VA}$. Setelah gardu KD 056 diseimbangkan dapat menurunkan drop tegangan dan rugi rugi daya, dengan demikian tegangan sistem memenuhi standar dari PLN.
\end{abstract}

Kata kunci : JTR, Ketidakseimbangan Beban, Pemerataan beban

\begin{abstract}
Load balancing is a routine done by PLN to manage a distribution substation. It is done on Peak Load Time (WBP) only. Initial load measurements and load data on a distribution transformer need to be done for balancing as input of simulation software. The load imbalance in a power distribution system is due to an imbalance in single phase loads in the $R, S$ and $T$ phases in low voltage networks due to the imbalance of the load the current in the neutral transformer arises. The current flowing in the neutral of the transformer causes losses, i.e. losses due to neutral currents in the neutral conductor of transformers and losses due to neutral currents flowing to the ground. In this research load equalization in substation KD 056 was done by making a simulation on the ETAP program by measuring the value of the voltage on the KD 056 substation. The result of load balancing in KD 056 substation with the simulation ETAP program i.e. the voltage drop obtained from the percentage of $K D 056$ substation after being balanced by voltage drop on phase $R$ which decreased from $7.30 \%$ to $1.36 \%$ from the $219 \mathrm{VA}$ source voltage. Once the KD 056 substation is balanced, it can lower the voltage drop and power losses, thus the system voltage meets the standards of PLN.
\end{abstract}

Keywords : JTR, Load imbalance, Load equalization

\section{PENDAHULUAN}

Gardu distribusi merupakan suatu bangunan gardu listrik terdiri dari instalasi Perlengkapan Hubung Bagi Tegangan Menengah (PHB-TM), Transformator Distri- busi (TD) dan Perlengkapan Hubung Bagi Tegangan Rendah (PHB-TR) untuk Memasok tenaga listrik bagi para pelanggan baik dengan Tegangan Menengah (TM 20 $\mathrm{kV}$ ) maupun Tegangan Rendah (TR 220 / 
380V). Tegangan primer $20 \mathrm{KV}$ lalu diubah oleh gardu distribusi menjadi tegangan sekunder $400 \mathrm{~V}$ (antar fasa) atau $220 \mathrm{~V}$ (fasa - netral). Pelanggan yang menggunakan adalah pelanggan Tegangan Rendah (TR), baik industri maupun rumah tangga.

Penyeimbangan beban gardu distribusi merupakan suatu rutinitas yang dilakukan oleh PLN dalam rangka manajemen sebuah gardu distribusi. Jumlah Pertumbuhan pelanggan PLN tidak sama disetiap fasa. Ketidakseimbangan beban juga terjadi akibat putus dalam berlangganan pengguna energi listrik PLN, maka akan terjadi perbedaan setiap fasa. Keadaan beban yang terus berubah, maka perlu dilakukan penyeimbangan beban secara berkala.

Penyeimbangan beban pada suatu trafo belum menjamin tercapainya keseimbangan beban di titik Luar Waktu Beban Puncak (LWBP). Penyeimbangan dilakukan dengan metode seimbang beban seharian (SBS) melalui proses simulasi. Penggunaan simulasi terlebih dahulu dapat meningkatkan efektifitas dan efisiensi dari kegiatan penyeimbangan beban. Pengukuran awal beban pada sebuah trafo distribusi perlu dilakukan untuk penyeimbangan sebagai input software simulasi. Penyeimbangan dilakukan merujuk pada hasil simulasi, sehingga keseimbangan antar fasanya tercapai disemua titik waktu kurva beban [1].

Beberapa penelitian mengenai Pemerataan beban pada penyulang yang sudah ada sebelumnya, penelitian yang dilakukan oleh Saputra pada tahun 2015 dengan judul "Analisis Pemerataan Beban Gardu Distribusi U 046 PT PLN (Persero) Rayon Ampera Palembang". Penelitian ini menyelidiki ketidakseimbangan beban masing - masing fasa pada transformator distribusi. Penelitian ini dilakukan dengan pengukuran dan perhitungan arus pada penghantar netral. Untuk mengurangi arus pada penghantar netral dilakukan pemerataan beban [2]. Penelitian yang dilakukan Priadi pada tahun 2014 yaitu: "Evaluasi untuk Mengatasi Beban Lebih Pada Penyulang Batu Belig". Tujuan dari penelitian ini adalah untuk memperoleh solusi yang tepat untuk mengatasi beban yang sudah kritis pada penyulang Batu Belig dan untuk Mendapatkan nilai losses dan drop tengangan penyulang Batu Belig pada saat sebelum dan sesudah dilakukan rekonfigurasi jaringan distribusi [3]. Serta penelitian yang di- lakukan Antara pada tahun 2010 mengenai "Rekonfigurasi Jaringan Tegangan Rendah (JTR) untuk Memperbaiki drop tegangan di Daerah Banjar Tulangnyuh Klungkung". Tujuan dari penelitian ini adalah untuk menganalisis besarnya drop tengangan dan rekonfigurasi jaringan untuk memperbaiki drop tegangan di daerah Banjar Tulangnyuh Klungkung [4].

Pertumbuhan jumlah penduduk pada daerah Kediri Tabanan meningkatkan jumlah pelanggan baru yang mengakibatkan transformator distribusi bekerja kurang optimal. Salah satu yang menyebabkan kerja transformator distribusi berkurang adalah adanya arus pada penghantar netral yang menyebabkan adanya rugi-rugi penghantar yang diakibatkan oleh ketidakseimbangan beban pada jaringan distribusi tegangan rendah di daerah Kediri Tabanan.

Berdasarkan latar belakang tersebut, maka perlu dilakukan sebuah penelitian dengan judul "Analisis Pemerataan Beban Pada Penyulang Tabanan Gardu KD 056 PT PLN (Persero) Distribusi Bali Area Bali Selatan Rayon Tabanan" yang bertempat di Desa Sanggulan Kecamatan Kediri Kabupaten Tabanan Bali untuk memperoleh kerugian dari beban yang tidak seimbang pada gardu distribusi KD 056.

\section{Tinjauan Pustaka \\ 2.1 Pengertian Umum}

Suatu sistem tenaga listrik yang lengkap mengandung empat unsur. Pertama, pembangkit tenaga listrik. Kedua, transmisi, lengkap dengan gardu induk. Karena jaraknya yang jauh, maka diperlukan penggunaan tegangan tinggi (TT), atau tegangan extra tinggi (TET). Ketiga, distribusi, yang biasanya terdiri atas saluran distribusi primer tegangan menengah (TM) dan saluran distribusi sekunder tegangan rendah (TR). Keempat, pemakaian (utilisasi), yang terdiri atas instalasi pemakaian tenaga listrik. Instalasi rumah tangga menggunakan tegangan rendah, sedangkan pemakai besar seperti industri mempergunakan tegangan menengah. Gambar 1 memperlihatkan skema suatu sistem tenaga listrik.

Mendekati pusat pemakaian tenaga listrik, yang dapat merupakan suatu industri atau kota, tegangan tinggi diturunkan menjadi tegangan menengah (TM). Di Indonesia tegangan menengah adalah $20 \mathrm{KV}$. Saluran $20 \mathrm{KV}$ ini menelusuri jalan-jalan diseluruh 
kota, dan merupakan sistem distribusi primer [5].
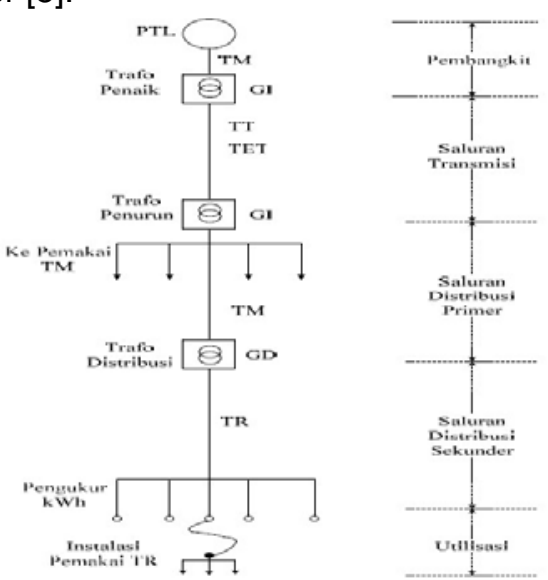

Gambar 1 Sistem Tenaga Listrik

Di Indonesia, tegangan rendah adalah 220/380 volt, dan merupakan sistem distribusi sekunder, disebut jaringan tegangan rendah (JTR). Jaringan Tegangan Rendah adalah penyaluran tenaga listrik dimulai dari sisi sekunder trafo distribusi yang mencakup seluruh bagian jaringan beserta perlengkapannya, sampai ke Alat Pengukurdan Pembatas (APP) beban. Drop tegangan adalah tegangan yang dikirim tidak sama dengan tegangan yang diterima beban, karena arus (I) yang mengalir disepanjang penghantar berbanding lurus dengan tahanan $(R)$, sementara besarnya rugi-rugi daya sepanjang jaringan adalah kuadrat arus $\left(\mathrm{I}^{2}\right)$ dikali tahanan penghantar jaringan (R).

Besar arus beban berbeda-beda disetiap fasa $R, S, T$ sepanjang jaringan, menimbulkan pembebanan pada trafo sekunder akibat beban tidak seimbang, Arus netral akan mengalir ke bumi melalui penghantar pembumian, maka sulit menghitung rugi-rugi daya keseluruhan dari saluran penghantar tersebut. Penelitian ini menggunakan beberapa asumsi dan hasil perhitungan yang diperoleh bukanlah hasil sebenarnya akan tetapi merupakan hasil pendekatan.

\section{METODELOGI PENELITIAN}

\subsection{Lokasi dan Waktu Penelitian}

Penelitian ini dilakukan di PT.PLN (Persero) Distribusi Bali Area Bali Selatan Rayon Tabanan. Sedangkan waktu penelitian ini dilaksanakan mulai hari Rabu 1 Juni 2016 sampai hari Kamis 30 Juni 2016.

\subsection{Sumber dan Jenis Data Penelitian}

\subsubsection{Sumber Data}

Data yang dipergunakan pada analisis Tugas Akhir ini bersumber dari PT.PLN (Persero) Distribusi Bali Area Bali Selatan Rayon Tabanan, dan hasil Pengukuran pada lokasi tempat melakukan penelitian yaitu di daerah penyulang tabanan KD 056 berlokasi di Desa Sanggulan Kecamatan Kediri Kabupaten Tabanan Bali.

\subsubsection{Jenis Data}

Data - data yang di pakai dalam analisis adalah data primer yang di dapat dari pengukuran langsung pada lokasi Penyulang Tabanan gardu KD 56 Rayon Tabanan yaitu data penyeimbangan beban /nilai ukur tegangan dan data sekunder yang di dapat adalah dari PT.PLN (Persero) Distribusi Bali Area Bali Selatan Rayon Tabanan yaitu data-data karakteristik penghantar, nilai pengukuran tegangan, diagram segaris dan penyeimbangan beban terakhir [6].

\subsection{Alur Analisis} berikut:

Alur analisis yang dilakukan sebagai

1. Pengumpulan data yang akan diseimbangkan seperti Single line diagram jumlah konsumen pada gardu KD 056

2. Memodelkan pemerataan beban menggunakan software ETAP 12.6

3. Mensimulasikan aliran daya pemerataan beban menggunakan software ETAP 12.6 (Beban tidak seimbang)

4. Melakukan penyeimbangan beban dengan cara rekonfirgurasi (pada program ETAP 12.6)

5. Analisis pemerataan beban (membandingkan hasil perhitungan dengan simulasi, membandingkan hasil simulasi sebelum dan setelah regunfigurasi JTR)

6. Menarik kesimpulan

\section{HASIL DAN PEMBAHASAN}

4.1 Hasil

Berikut ini adalah hasil perbandingan keseimbangan beban pada gardu KD 056 Rayon Tabanan sebelum diseimbangkan dan sesudah diseimbangkan yang dapat dilihat pada Tabel 1.

Tabel 1 menunjukkan setelah gardu KD 056 diseimbangkan drop tegangan 
pada phasa $\mathrm{R}$ berkurang dari (203) menjadi (216). Untuk hasil persentase pada phasa $\mathrm{R}$ dapat dilihat pada Tabel 2 .

Hasil persentase gardu KD 056 setelah diseimbangkan drop tegangan pada phasa $\mathrm{R}$ berkurang dari $7,30 \%$ menjadi 1,36\%. Gardu KD 056 yang diseimbangkan dapat menurunkan drop tegangan dan rugi rugi daya.Tegangan sistem pada Gardu KD 056 semakin menjadi lebih baik dan telah memenuhi standar dari PLN yaitu (SPLN 72,1987).

Tabel 1 Perbandingan keseimbangan beban

\begin{tabular}{|c|c|c|c|c|}
\hline \multicolumn{2}{|c|}{ NAMA GARDU } & KD 056 & KD 056 \\
\hline \multicolumn{2}{|c|}{ KONDISI } & & Sebelum Diseimbangkan & Sesudah Diseimbangkan \\
\hline \multirow{3}{*}{ BEBAN (kVA) } & \multirow{3}{*}{ Phasa } & R & $19.950 \mathrm{VA}$ & $14.650 \mathrm{VA}$ \\
\cline { 3 - 5 } & & $\mathrm{S}$ & $14.650 \mathrm{VA}$ & $14.650 \mathrm{VA}$ \\
\cline { 3 - 5 } & & $\mathrm{T}$ & $9.300 \mathrm{VA}$ & $14.600 \mathrm{VA}$ \\
\hline \multirow{3}{*}{ TEGANGAN (Volt) } & \multirow{3}{*}{ Phasa } & R & 203 & 216 \\
\cline { 3 - 5 } & & S & 211 & 211 \\
\cline { 3 - 5 } & & $\mathrm{T}$ & 219 & 215 \\
\hline
\end{tabular}

Tabel 2 Persentase Perbandingan keseimbangan

\begin{tabular}{|c|c|c|c|}
\hline \multicolumn{2}{|c|}{ NAMA GARDU } & KD 056 & KD 056 \\
\hline \multicolumn{2}{|c|}{ KONDISI } & Sebelum Diseimbangkan & Sesudah Diseimbangkan \\
\hline TEGANGAN(Volt) & Phasa & 203 & 216 \\
\hline \multicolumn{2}{|c|}{ Droop Teg. Dari Teg Sumber (219V) (\%) } & $7,30 \%$ & $1,36 \%$ \\
\hline
\end{tabular}

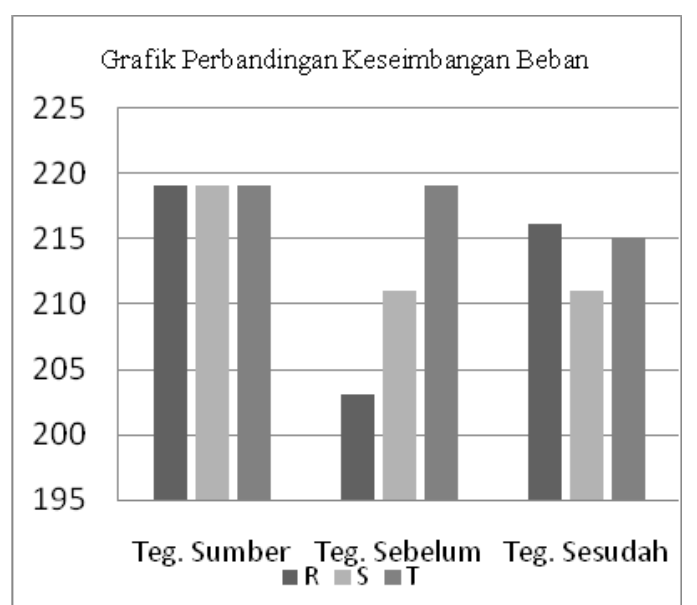

Gambar 2 Grafik Perbandingan Keseimbangan Beban

Grafik perbandingan keseimbangan beban pada phasa $\mathrm{R}, \mathrm{S}$ dan $\mathrm{T}$ dapat dilihat pada Gambar 2.

\subsection{Pembahasan}

\subsubsection{Gambaran Umum Gardu KD 056}

Gardu KD 065 berlokasi di $\mathrm{Br}$. Sanggulan Kediri Tabanan dengan kapasitas beban maksimum 160kVA yang digunakan untuk menyuplai listrik ke dua banjar yaitu banjar taman sari dan banjar dinas sanggulan. Pada Tabel 3 dapat diperlihatkan data karakteristik gardu trafo KD 056.

Tabel 3 Data Karakteristik Gardu Trafo KD 056

\begin{tabular}{|l|l|}
\hline Karakteristik & Keterangan \\
\hline ID Trafo & 37113860 \\
\hline Nomor Gardu & KD 0056 \\
\hline Penyulang & Tabanan \\
\hline Nomor Seri & 55131 \\
\hline Tahun Pembuatan & 2012 \\
\hline Jumlah Jurusan & 2 \\
\hline Merk & TAIYA \\
\hline Kapasitas max (kVA) & 160 \\
\hline Kapasitas Trafo (kVA) & 160 \\
\hline Status Trafo & Tidak Over Blast \\
\hline
\end{tabular}

\subsubsection{Sistem Jaringan Tegangan Rendah (JTR) Trafo KD 056}

Sistem jaringan Trafo KD 056 adalah sistem radial yaitu disuplai oleh penyulang Tabanan kemudian disalurkan ke seluruh pelanggan secara radial pula. Trafo KD 056 mempunyai kapasitas maksimum 160kVA digunakan untuk menyuplay beban terukur dengan total daya 43.900VA dalam persentase itu sebanyak $27,4 \%$ artinya trafo KD056 mempunyai sisa $72,6 \%$ dan belum over blast. Ini sesuai dengan pengukuran data trafo pada saat beban puncak (jam 19.00 tanggal 30 Juni 2016). Phasa R,S dan T pada JTR gardu KD056 saat ini ditunjukan pada Gambar 3. 


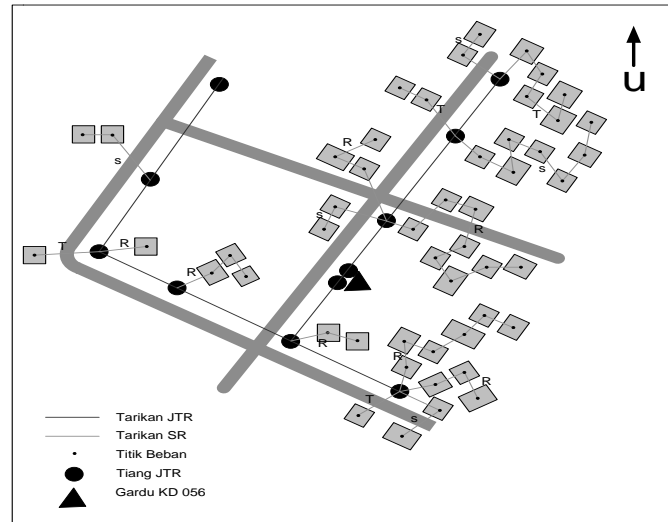

Gambar 3 Beban yang Terpasang Pada Phasa R, S dan $\mathrm{T}$

\subsubsection{Besar Kerugian dari Beban Tidak Seimbang pada Gardu KD 056 Sebelum Di} Seimbangkan

Gardu KD 056 dengan total panjang Jaringan Tegangan Rendah (JTR) yang terpasang adalah $308 \mathrm{~m}$ dengan beban masing-masing phasa yang terpasang adalah $\mathrm{R}=19.950 \mathrm{VA}, \mathrm{S}=14.650 \mathrm{VA}$ dan $\mathrm{T}$ $=9.300 \mathrm{VA}$, Pelanggan gardu KD 056 memiliki karakteristik beban yang berbedabeda. Beban-beban pada gardu KD 056 terletak pada perumahan dan fasilitas umum.

Kondisi JTR KD 056 sebelum diseimbangkan (Tahun 2016) meliliki data-data sebagai berikut:

a. Total Beban Terpasang : 43.900VA atau 43,9kVA

b. Jumlah pelanggan : 50 Pelanggan

c. Konfirgurasi jaringan : Sistem radial

d. Jenis penghantar : LVTC

Lebih jelasnya, penghantar yang digunakan pada JTR gardu KD 056 dapat dilihat dalam Tabel 4 dan gambar jaringan (JTR) gardu KD056 sebelum diseimbang ditunjukan pada Gambar 4.

Tabel 4 Data Penghatar

\begin{tabular}{|c|c|c|}
\hline $\begin{array}{c}\text { TIPE } \\
\text { JTR }\end{array}$ & JENIS PENGHANTAR & $\begin{array}{c}\text { PANJANG } \\
(\mathrm{m})\end{array}$ \\
\hline SKUTR & MVTIC $3 \times 70+1 \times 50 \mathrm{~mm}^{2}$ & $\mathbf{6 5 0}$ \\
\hline SKUTR & LVTC $2 \times 10 \mathrm{~mm}^{2}$ & $\mathbf{1 . 1 8 0}$ \\
\hline & Total Panjang Jaringan & 1.830 \\
\hline
\end{tabular}

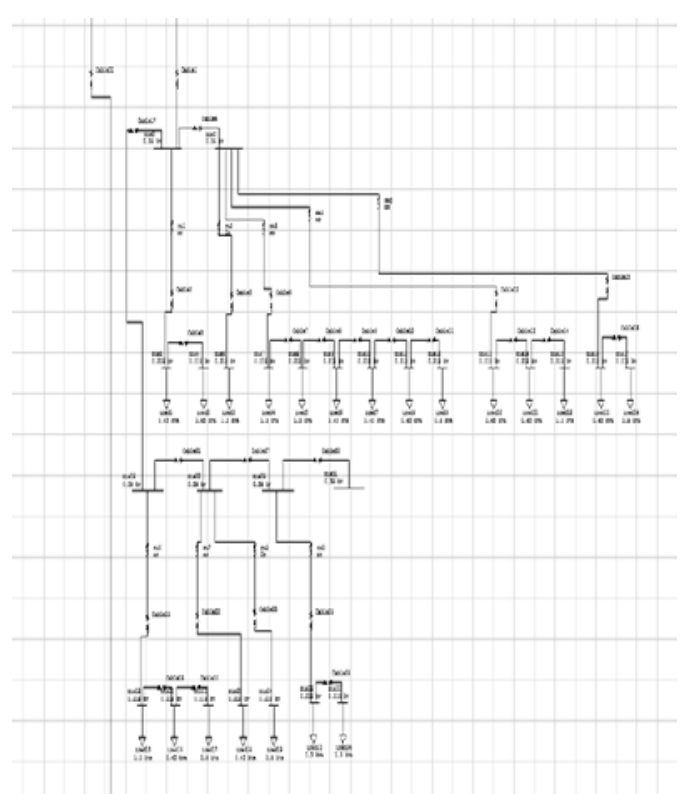

Gambar 4 JTR Gardu 056 Sebelum Diseimbangkan Secara keseluruhan jumlah pelanggan gardu KD 056 adalah 50 pelanggan yang terdiri dari pelanggan rumah tangga yaitu beban 1 phasa, dan beban fasilitas umum 1 phasa. Total daya kontrak atau beban terpasang pada gardu kd 056 adalah 43.900VA atau 43,9kVA.

\section{a. Data Jumlah Beban dan Rata- Rata Tegangan Pemakaian pada Gardu KD 056 Sebelum Diseimbangkan}

Berdasarkan hasil pengukuran langsung pada gardu KD 056 pada banjar sanggulan pada beban puncak diperoleh data tegangan masing-masing phasa yang terpasang dengan menggunakan alat ukur tang amphere standar PLN merk KYORITSU model Clamp meter Kew SNAP 2022PA dan KYORITSU model Clamp meter 2017 didapatkan data pengukuran yang sama yaitu ditunjukan dalam Tabel 3 .

Pada Tabel 3 adalah nilai beban yang terukur pada phasa JTR yang diukur. Tegangan terendah terjadi pada phasa $R$ dimana tegangan yang terukur sebesar 203V. Data ini nantinya dipergunakan dalam analisa dengan program ETAP power ststion 12.6.
b. Analisa Tegangan Sebelum Diseimbangkan Berdasarkan Program ETAP Powerstation 12.6


Besarnya tegangan di masingmasing bus beban pada pelanggan yaitu dianalisa menggunakan program ETAP Powerstation 12.6 cara analisa adalah masukkan data bus JTR dan bus beban, data kapasitas trafo, data impedansi kabel penghantar, data nilai pembebanan pada pelanggan dan data panjang kabel.

Nilai tegangan hasil analisa Program ETAP Powerstation 12.6 ditampilkan pada Gambar 5.

Tabel 5 Data Beban Pada Phasa R,S dan T pada JTR Gardu KD 056

\begin{tabular}{|c|c|c|}
\hline PHASE & $\begin{array}{c}\text { BEBAN TERPASANG } \\
\text { (VA) }\end{array}$ & $\begin{array}{c}\text { TEGANGAN } \\
\text { (Volt) }\end{array}$ \\
\hline $\mathrm{R}$ & $19,950 \mathrm{VA}$ & 203 \\
\hline $\mathrm{S}$ & $14,650 \mathrm{VA}$ & 211 \\
\hline $\mathrm{T}$ & $9,300 \mathrm{VA}$ & 219 \\
\hline
\end{tabular}

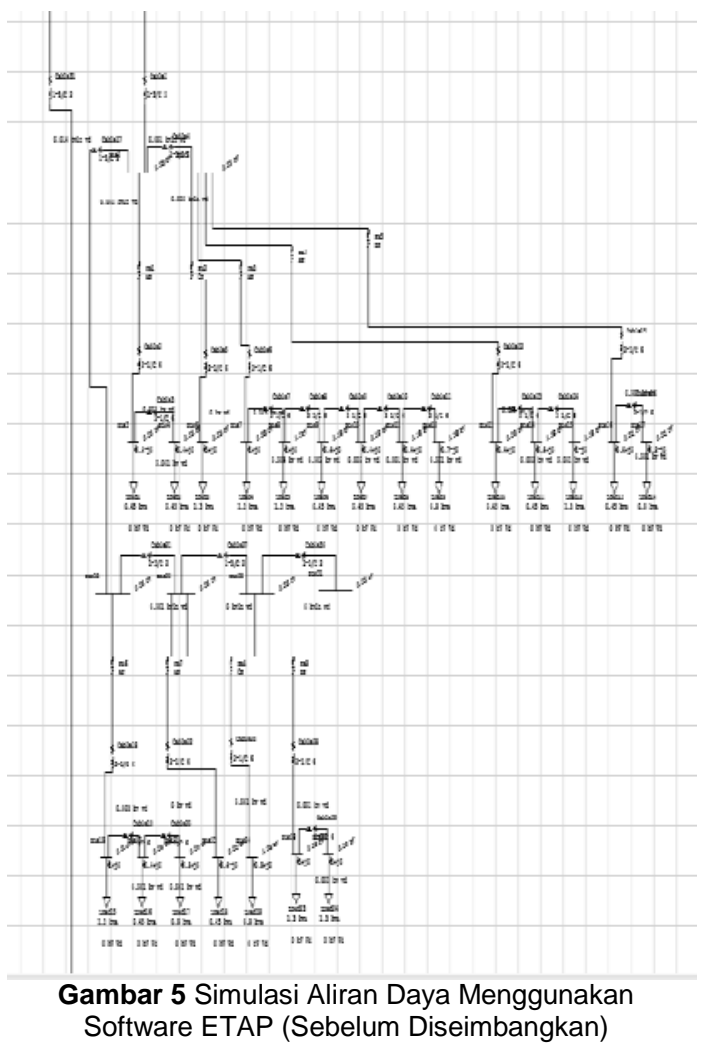

Tabel 6 Data Persentase Tegangan Pada Phasa R,S dan T pada JTR Gardu KD 056

\begin{tabular}{|c|c|c|c|}
\hline $\begin{array}{c}\text { PHAS } \\
\text { A }\end{array}$ & $\begin{array}{c}\text { BEBAN } \\
\text { TERPASAN } \\
\text { G (VA) }\end{array}$ & $\begin{array}{c}\text { TEGANGA } \\
\text { N (Volt) }\end{array}$ & $\begin{array}{c}\text { DROP } \\
\text { TEGANGA } \\
\text { N (\%) }\end{array}$ \\
\hline R & 19,950 VA & 203 & 7,30 \\
\hline S & 14,650 VA & 211 & 3,65 \\
\hline T & 9,300 VA & 219 & 0,00 \\
\hline
\end{tabular}

Tabel 6 menunjukkan diatas jumlah tegangan yang terpasang 43.900 VA yang dirata-ratakan dibagi menjadi 3 phase R, S, dan $T$ menjadi 14.633VA dan besarnya drop tegangan pada phasa R Gardu KD056 adalah 7,30\%. Menurut standar PLN (SPLN 72,1987) drop tegangan yang diijinkan untuk JTR tipe radial tidak boleh melebihi 5\%. Gardu KD056 memiliki drop tegangan melebihi $5 \%$ dari standar yang diijinkan, harus dilakukan penyeimbangan.

\subsubsection{Cara Melakukan Pemerataan Beban Pada Gardu KD 056 \\ Analisis ketidakseimbangan beban} pada program ETAP Powerstation 12.6 dijelaskan sebagai berikut:

1. Pertama-tama adalah memasukkan data bus pada JTR dan beban,data kapasitas trafo,data impedansi kabel penghantar, data panjang kabel penghantar dan data nilai masing - masing pembebanan pada pelanggan sesuai dengan data penelitian yang didapat dengan memperhatikan cara-cara penggunaan program ETAP.

2. Data beban dilapangan adalah beban 1 phasa. Analisa yang dilakukan oleh program yaitu analisa aliran daya pada JTR per phasa.

3. Rata - rata jumlah tegangan per phasa ditentukan dari Tabel 6.

Setelah mengetahui cara analisis program ETAP Powerstation 12.6, maka dilakukanlah penyeimbangan beban dengan meratakan jumlah phasa pada program etap dengan membagi 2 tarikan SR phasa R ke phasa T dengan jumlah 7 pelanggan dengan beban sejumlah 5.300VA dari 19.950VA menjadi 14.633VA sehingga memenuhi rata-rata beban yaitu 14.633VA yang ditunjukkan pada Gambar 6.

Gambar 6 menunjukkan pemindahan phasa dengan jumlah 7 pelanggan dengan beban sebanyak 5.300 VA, dan hasil yang di dapat pun jumlah beban yang diperoleh masing masing phasa dapat dilihat dari Tabel 7. 


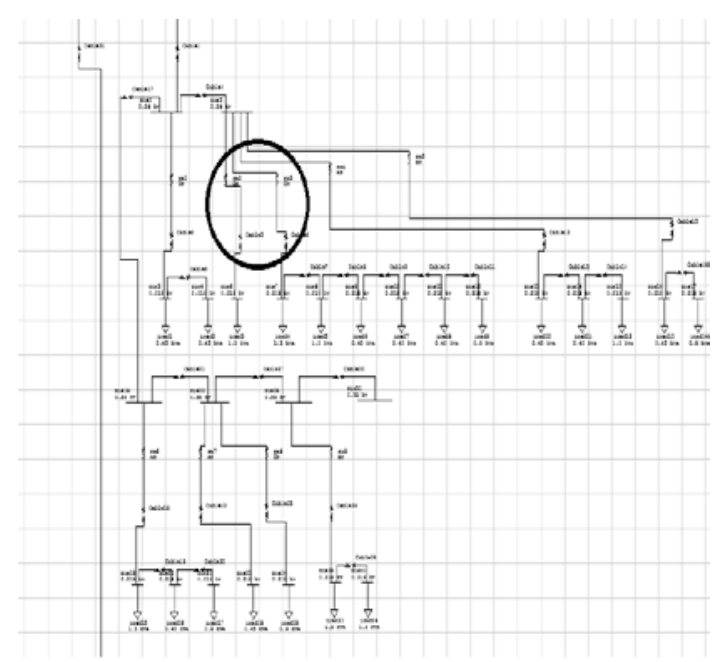

Gambar 6 JTR Gardu KD 056 Setelah Diseimbangkan

Tabel 7 Data Beban Setelah Diseimbangkan

\begin{tabular}{|c|c|c|}
\hline PHASA & $\begin{array}{c}\text { BEBAN } \\
\text { TERPASANG (VA) }\end{array}$ & $\begin{array}{c}\text { TEGANGAN } \\
\text { (Volt) }\end{array}$ \\
\hline $\mathrm{R}$ & $14.650 \mathrm{VA}$ & 216 \\
\hline $\mathrm{S}$ & $14.650 \mathrm{VA}$ & 211 \\
\hline $\mathrm{T}$ & 14.600VA & 215 \\
\hline
\end{tabular}

Tabel 7 diatas menunjukkan setelah dilakukan penyeimbangan beban, tegangan phasa $R$ yang sebelumnya terendah berubah menjadi $216 \mathrm{~V}$ dari sumber $219 \mathrm{~V}$. Sehingga drop tegangan dinyatakan dalam persentase adalah drop tegangan pada phasa $\mathrm{R}$ berubah menjadi $1,36 \%$, phasa $\mathrm{S}$ tetap $3,65 \%$ dan phasa $\mathrm{T}$ berubah menjadi $1,82 \%$. Sedangkan menurut standar (SPLN) drop tegangan yang dijinkan untuk JTR tipe radial adalah tidak melebiki $5 \%$. Sehingga dalam hal ini, drop tegangan pada JTR Gardu KD 056 sudah memenuhi standar (SPLN) yang diijinkan.

\section{SIMPULAN DAN SARAN}

\subsection{Simpulan}

Pemerataan beban gardu KD 056 PT

PLN (Persero) rayon Tabanan menggunakan aplikasi ETAP dapat disimpulkan:

1. Ketidakseimbangan beban pada gardu KD 056 PT PLN (Persero) rayon Tabanan pada phasa $\mathrm{R}$ drop tegangan sebelum diseimbangkan sebesar $7,30 \%$ dan setelah diseimbangkan menjadi $1,36 \%$.

2. Pemerataan beban dilakukan dengan cara memindahkan sambungan listrik pelanggan dari phasa satu ke phasa yang lain (phasa R ke phasa $T$ ) sampai beban dari ketiga phasa $\mathrm{R}, \mathrm{S}$ dan $\mathrm{T}$ seimbang atau mendekati seimbang.

3. Aplikasi ETAP sebagai inovasi dalam menganalisis proses kelistrikan sangat efektif untuk membantu dalam melakukan simulasi pemerataan beban seperti tegangan pada phasa $\mathrm{R}, \mathrm{S}$ dan $\mathrm{T}$.

\subsection{Saran}

Untuk menghindari pemerataan beban yang terus menerus sebaiknya dilakukan penyambungan pada pelanggan baru harus memperhatikan phasa yang digunakan dari gardu distribusi agar tidak terjadi penumpukan pada satu phasa yang menyebabkan beban tidak seimbang.

\section{DAFTAR PUSTAKA}

[1] Abdillah, F. 2014.Penyeimbang Beban Pada Gardu Distribusi Dengan Metode Seimbang Beban Seharian Di PT. PLN Area Bukittinggi

[2] Saputra, 2015. Analisa Pemerataan Beban Gardu Distribusi U 046 PT PLN (Persero) Rayon Ampera Palembang.

[3] Priadi, 2014. Evaluasi untuk Mengatasi Beban Lebih Pada Penyulang Batu Belig

[4] Antara. 2015. Rekonfigurasi Jaringan Tegangan Rendah (JTR) untuk Memperbaiki Drop Tegangan di Daerah Banjar Tulangnyuh Klungkung

[5] Kadir, A. 2000. Distribusi Dan Utilisasi Tenaga Listrik. Jakarta: Universitas Indonesia (UI-Press).

[6] PT PLN (PERSERO). 2010. Buku Standar Konstruksi Gardu Distribusi Dan Gardu Hubung Tenaga Listrik. Jakarta Selatan : PT PLN (PERSERO). 